\title{
Retraducción y calidad: el caso de Madame Bovary ${ }^{1}$
}

\author{
Hernández-Guerrero, María José
}

Universidad de Málaga, mjhernandez@uma.es

\begin{abstract}
Resumen
Madame Bovary es la novela de Flaubert más traducida al castellano. Desde la primera versión de Amancio Peratoner en 1875 hasta la más reciente, de 2014, obra de Javier Albiñana, se han publicado en castellano solo en la Península unas cuarenta traducciones de esta obra. Sus frecuentes retraducciones hablan de un interés ininterrumpido por este clásico y lo convierten en un interesante caso de estudio, ya que, aunque parece aceptada la premisa de que cada generación necesita dotarse de una traducción propia de las obras de referencia universal, en el caso de Madame Bovary resulta evidente que la profusión de retraducciones que se ha venido produciendo en los últimos años responde a mecanismos más complejos, que pretendemos abordar en este estudio. En concreto, nos proponemos averiguar si las nuevas traducciones de esta obra han supuesto una mejora de traducciones previas o si, más bien, responden a políticas del sector editorial.
\end{abstract}

Para ello, llevaremos a cabo una comparación de traducciones de Madame Bovary publicadas en los últimos años, que se centrará en fragmentos con imágenes del agua presentes en esta novela. Muchas de las imágenes de las que se sirve Flaubert proceden de la naturaleza, y entre ellas destaca por su uso la imagen del agua que fluye como símil de lo efímero, pero también con la función de preludio, de símbolos que se anticipan al lector como presagios. Utilizaremos ejemplos de traducciones pasadas y presentes para responder a los interrogantes anteriores.

Palabras clave: Madame Bovary; retraducción; calidad de las traducciones; política editorial.

\section{Résumé}

Madame Bovary est le roman de Flaubert le plus traduit en espagnol. Depuis la première version d'Amancio Peratoner (1875) jusqu'à la plus récente de Javier Albiñana, publiée en 2014, une quarantaine de traductions de cet ouvrage ont été publiées en castillan seulement en Espagne. Leurs fréquentes retraductions parlent d'un intérêt continu pour ce chef d'œuvre et en font une étude de cas intéressante. Le principe que chaque génération a besoin de se doter de sa propre traduction des ouvrages de référence universelle semble accepté, cependant dans le cas de madame Bovary il est évident que la profusion de retraductions qui s'est produite au cours des dernières années répond à des mécanismes plus complexes, que nous allons aborder dans cette étude. Plus précisément, nous avons l'intention de découvrir si les nouvelles traductions de ces travaux sont là pour améliorer les traductions précédentes ou si elles répondent plutôt aux politiques du secteur de l'édition.

Pour ce faire, nous allons établir la comparaison entre certaines des traductions de Madame Bovary publiées ces dernières années. Cette comparaison portera sur les images de l'eau présentes dans ce roman. Bon nombre des images dont Flaubert se sert procèdent de la nature, et parmi elles l'image de l'eau qui coule se distingue d'abord par son rapport à l'éphémère, mais aussi par sa fonction de prélude, de symbole à vocation de présage. Nous allons utiliser des exemples extraits des traductions passées et récentes pour répondre aux questions précédentes.

Mots-clés: Madame Bovary; retraduction ; qualité des traductions ; politique éditoriale.

\footnotetext{
${ }^{1}$ Este trabajo se enmarca en el proyecto de I+D La traducción de clásicos en su marco editorial: una visión transatlántica, ref. FFI2013-41743-P, financiado por el Ministerio de Economía y Competitividad.
} 


\begin{abstract}
Madame Bovary is the novel by Flaubert that has most often been translated into Spanish. From the first translation by Amancio Peratoner in 1875 to the most recent one in 2014 by Javier Albiñana, there have been forty Spanish translations of this work published in Spain alone. Its frequent retranslations reflect a continuous interest in this classic and make it an interesting case study because, although the premise that each generation must have its own translation of universally renowned literary works seems to be accepted, in the case of Madame Bovary it is obvious that the profusion of retranslations in recent years is attributable to more complex causes which we will address in this study. Our aim, in particular, is to discover if the new translations of this work represent an improvement on previous translations or if instead they are the result of politics in the publishing industry.

To this end, we will compare the translations of Madame Bovary published in recent years and this comparison will focus on fragments of text with water imagery. Much of the imagery that Flaubert uses comes from nature. Outstanding is his use of flowing water imagery as a simile for ephemerality and also as a prelude or portent of things to come for the reader. We will make use of examples from past and present translations to answer these questions.
\end{abstract}

Keywords: Madame Bovary; retranslation; quality in translations; politics in publishing.

\title{
Introducción
}

En los últimos años, el sector editorial ha mostrado un interés inusitado por Madame Bovary, obra de Gustave Flaubert. Giné Janer (2011), en un completo catálogo que recoge las traducciones al castellano de todas las obras de Flaubert, proporciona un exhaustivo recuento de las versiones de esta novela publicadas en la Península hasta el año 2009. Fondebrider (2014), por su parte, en su traducción de Madame Bovary, incluye un valioso anexo titulado «Las versiones de Madame Bovary» que ofrece información sobre todas las traducciones de esta obra a prácticamente todas las lenguas del planeta. Esta recopilación actualiza y completa los datos proporcionados por Giné Janer al incluir las traducciones publicadas en la otra orilla del Atlántico. Dejando al margen lagunas y errores presentes en ambas recopilaciones que, como señalábamos en un trabajo anterior (Hernández Guerrero, en prensa), no son achacables a sus compiladores -su labor no se ha centrado en el análisis de cuestiones como autoría de las traducciones, adaptaciones o plagios, sino en ofrecer un repertorio basado en las traducciones publicadas-, los datos que ofrecen hablan de un interés ininterrumpido y creciente por este clásico de Flaubert, que queda manifiesto en sus frecuentes retraducciones.

Madame Bovary ha generado una frenética actividad editorial y traductora. Desde la primera versión de Amancio Peratoner en 1875 hasta la más reciente, de 2014, obra de Javier Albiñana, se han publicado en castellano -solo en la Península- unas cuarenta traducciones de esta obra.

Hasta fechas muy recientes, los únicos estudios sobre las traducciones de Madame Bovary eran obra de un único investigador, el profesor y traductor Juan Bravo Castillo (1995 y 2009) quien, ante el encargo de una nueva traducción por parte de Espasa Calpe -que se publicó en 1993-, decidió hacer un balance de lo que se había hecho previamente y quedó negativamente sorprendido por la falta de calidad de las traducciones anteriores. Desde la traducción de Bravo Castillo hasta la fecha, Madame Bovary se ha traducido al español en la Península en trece ocasiones más (cf. Hernández Guerrero, en prensa).

En este trabajo nos proponemos averiguar si las nuevas traducciones de esta obra han supuesto una mejora de traducciones previas o si, más bien, responden a políticas del sector editorial. Para ello, hemos comparado las traducciones de Bravo Castillo (1993), Mersoye (2010), Gallego (2012); Armiño (2013) y Albiñana (2014). Por el rigor con el que fue realizada, hemos elegido como punto de partida la traducción de Bravo Castillo, que en su momento fue saludada por la crítica por su calidad (Bueno, 1995: 142). Motivos de espacio nos impiden ocuparnos de las trece traducciones posteriores por lo que nos hemos centrado en las cuatro últimas publicadas hasta la fecha ${ }^{2}$. Para la

${ }^{2}$ Finalizado este trabajo, hemos tenido conocimiento de la publicación en 2015 de una nueva traducción de Madame Bovary en la Península, obra de Pablo R. Nogueras, en la editorial Mestas. 
comparación, hemos utilizado determinados pasajes de la novela donde Flaubert recurre a descripciones con la imagen del río como agua que fluye, con diferente simbología.

\section{Traducciones de Madame Bovary: corpus utilizado}

Espasa Calpe publicó la traducción de Bravo Castillo en 1993, en su colección Austral. Desde entonces ha sido objeto de varias reediciones por parte de ese mismo sello y por parte de otros (Planeta-De Agostini, 2001). Esta traducción, junto con las cuatro últimas versiones españolas de Madame Bovary, forman el corpus utilizado en nuestro análisis. Las versiones más recientes han visto la luz en un breve lapso temporal. Son obra de Marie Mersoye (Plutón, 2010); M $^{\mathrm{a}}$ Teresa Gallego (Alba, 2012); Mauro Armiño (Siruela, 2013); y Javier Albiñaña (Vicens Vives, 2014). Todas ellas han surgido desde planteamientos editoriales distintos. La traducción de Bravo Castillo venía a sustituir a la de Pedro Vances (1923) en ese mismo sello, ya envejecida. Entraría en la categoría de lo que Pym (1998: 82) denomina retraducciones pasivas -aquellas que están separadas por una distancia geográfica o temporal y no rivalizan entre sí-, que en este caso se origina por el lenguaje desfasado o anticuado de la traducción previa.

Las restantes se han publicado en un contexto bien diferente, compitiendo con reediciones de traducciones anteriores y con nuevas retraducciones que no han dejado de sucederse. Estas últimas versiones entrarían en la categoría de lo que Pym (1998: 82-83) denomina retraducciones activas, es decir, textos surgidos en el mismo ámbito cultural y generacional que compiten entre sí y que tienen su origen en las políticas del sector editorial. Resulta evidente que su publicación no responde a la necesidad generacional de nuevas traducciones que tradicionalmente se ha señalado como una de las principales razones para la retraducción (Venuti, 2004: 25; Zaro, 2007: 32), sino a otros mecanismos más complejos.

La versión de Marie Mersoye, traductora apenas conocida, fue publicada en 2010 por Plutón Ediciones, joven sello barcelonés, y se presentó en formato bolsillo en la colección Eterna, dedicada a obras clásicas. No incluye ningún paratexto que informe sobre la traducción y no hemos encontrado ninguna referencia por parte de la crítica.

Alba Editorial publicó en 2012 una nueva versión de la novela de Flaubert en su colección Clásica Maior, a cargo de Mª Teresa Gallego. La crítica alabó desde un principio su calidad, pero en lo que más se detuvo, sin duda alguna, fue en la traducción del título: La señora Bovary. Por este trabajo, Gallego obtuvo el Premio Esther Benítez de Traducción en 2013.

En 2013, Siruela, en su colección Tiempo de Clásicos, presentaba una nueva Madame Bovary, con prólogo de Mario Vargas Llosa y edición y traducción de Mauro Armiño. En este caso, la crítica hizo hincapié en la calidad y en los tres fragmentos inéditos recuperados por el traductor como apéndice en su edición de este clásico. Esta misma traducción fue retomada en 2015 por Penguin, en su colección Clásicos.

Por último, Vicens Vives inauguraba su colección Clásicos Universales en 2014 con esta novela. Manteniéndose en su línea de productos orientados al sector educativo, la editorial ofrecía en este primer volumen una nueva traducción de Madame Bovary realizada por Javier Albiñana. Se trata de una edición en rústica muy cuidada, con ilustraciones al pastel encargadas expresamente al artista norteamericano Gary Kelley. La edición corre a cargo de los catedráticos Teresa Barjau y Joaquim Parellada, quienes también prologan y anotan la traducción, y son autores del estudio de la obra que se incluye al final.

En los tres últimos casos, es de reseñar la trayectoria profesional rica e intachable de los traductores, reconocida en numerosas ocasiones. Como también es de reseñar la calidad de las colecciones que acogen estas versiones, que ofrecen un marco digno de una obra como Madame Bovary.

\section{Análisis de traducciones: las imágenes del río}

Cinco años tardó Flaubert en terminar Madame Bovary. Convencido de que solo la forma podía dar a su obra un valor eterno, son conocidos los esfuerzos y la dedicación autoimpuestos en su escritura para lograr lo que él denominaba «la armonía sostenida del estilo». Desde el punto de vista formal, el resultado fue excepcional. Frente al uso tradicional de la imagen, presente en casi todos los escritores, Flaubert desarrolla un procedimiento singular, muy sofisticado: la serie 
de imágenes (Hardt, 2014). Se trata de imágenes reiteradas, unidas, como una red que mantiene el recuerdo de la precedente y que actúa como preludio de la siguiente. A través de este recurso, cuenta una historia. La serie de imágenes funciona como un segundo plano simbólico de la trama. Hardt destaca la imagen de la llama, del fuego, del mar (navegar a la deriva) y, sobre todo, por su abundancia, la imagen del río: el agua que fluye, como símil de lo efímero, del discurrir, de lo fugaz, de la disolución. La presencia del río es recurrente en Madame Bovary y refleja la voluntad de su autor de permanecer fiel a su marco geográfico. Al mismo tiempo, el río discurre en paralelo a la intriga para describir, poner de manifiesto o subrayar cambios psicológicos en los personajes.

Nos hemos servido de estas imágenes para medir la calidad de las traducciones analizadas. Ante la imposibilidad de reproducirlas todas, hemos optado por las más representativas que presentamos en los cuatro siguientes ejemplos. Cada uno de ellos presenta una breve descripción del contexto, el fragmento original y sus traducciones, junto con un comentario al respecto.

\section{Ejemplo 1 - Madame Bovary, II, 3}

De camino a casa de la nodriza, Emma se encuentra con Léon y le pide que la acompañe. Finalizada la visita, vuelven por la orilla del río. La conversación languidece y se llena de silencios.

Dans la saison chaude, la berge plus élargie découvrait jusqu’à leur base les murs des jardins, qui avaient un escalier de quelques marches descendant à la rivière. Elle coulait sans bruit, rapide et froide à l’œil ; de grandes herbes minces s’y courbaient ensemble, selon le courant qui les poussait, et comme des chevelures vertes abandonnées s'étalaient dans sa limpidité (Flaubert, 135).

Durante la época del estío, la ribera, más ancha, dejaba al descubierto hasta su base las tapias de las huertas, de las que solían arrancar varios escalones que bajaban hasta el río. Discurría este silencioso, rápido y visiblemente frío; altas y delgadas hierbas se curvaban juntas en la superficie, al azar de la corriente, y se reflejaban en su limpidez como verdes y abandonadas cabelleras (Trad. de Bravo, 171).

En el verano, el ribazo pelado descubría casi hasta su base los muros de los jardines, que tenían una escalera de algunos escalones que bajaba al río; éste se deslizaba silencioso, rápido y frío a la vista; grandes hierbas delgadas se encorvaban al empuje de la corriente, y como cabelleras verdes se extendían en su limpidez. (Trad. de Mersoye, 103)

En la estación de los calores; la ribera, más despejada, dejaba al aire la parte de debajo de las tapias de los jardines, que tenían una escalera de pocos peldaños que bajaba hasta el río. Éste corría sin ruido y, al mirarlo, parecía frío y veloz; se curvaban juntas en él largas hierbas delgadas, en la dirección que disponía la corriente, y se extendían por el agua límpida como melenas verdes abandonadas (Trad. de Gallego, 120).

En la estación cálida, la ribera, más ancha, dejaba al descubierto hasta su base las tapias de las huertas, que tenían una escalera de varios peldaños descendiendo hasta el río, que fluía sin ruido, rápido y frío a la vista; grandes hierbas delgadas se doblaban juntas, según la corriente que las empujaba, y se extendían en su limpidez como verdes cabelleras abandonadas (Trad. de Armiño, 133).

En el periodo estival, el margen más ancho dejaba al descubierto hasta la base los muros de los huertos, de los que descendía una escalera de unos cuantos peldaños hasta el río. Este fluía en silencio, rápido y frío a simple vista; grandes y delgadas hierbas se curvaban al unísono, según el empuje de la corriente, y se desplegaban, cual desoladas cabelleras verdes, en la limpidez de las aguas (Trad. de Albiñana, 130).

Todas las traducciones reflejan el original con las variaciones propias derivadas de la visión de cada traductor y similar calidad, excepto la de Mersoye de menor riqueza expresiva y donde se aprecia la omisión de varios adjetivos. En la traducción de Gallego, se ha puntuado incorrectamente en el caso del punto y coma de la primera línea.

Ejemplo 2 - Madame Bovary, II, 6

Contemplando el paisaje, ociosa, Emma oye el toque del ángelus y siente el impulso de acudir a la iglesia. El paisaje nebuloso por los vapores del río es un reflejo de su malestar vital. 
Un soir que la fenêtre était ouverte, et que, assise au bord, elle venait de regarder Lestiboudois, le bedeau, qui taillait le buis, elle entendit tout à coup sonner l'Angelus. [...] Par les barreaux de la tonnelle et au delà tout alentour, on voyait la rivière dans la prairie, où elle dessinait sur l'herbe des sinuosités vagabondes. La vapeur du soir passait entre les peupliers sans feuilles, estompant leurs contours d'une teinte violette [...] (Flaubert, 155).

Una tarde Emma estaba sentada junto a la ventana abierta. Acababa de ver a Lestiboudois, el sacristán, podando el boj, cuando de repente oyó el toque del Angelus. [...] Por entre el enrejado del cenador se percibía a lo lejos, en la pradera, el río dibujando sus vagabundas sinuosidades sobre la hierba. El vaho del atardecer ascendía por entre los desnudos álamos, difuminando sus contornos con un tono violáceo [...] (Trad. de Bravo, 187).

Cierta tarde, abierta la ventana, y sentada ante ella, mirando a Lestiboudois, que se entretenía torneando un palo, escuchó Emma el toque del Angelus. [...] Por el enrejado del cenador, allá abajo, se veía el río dibujando en la pradera su marcha sinuosa; los vapores de la tarde pasaban por entre los álamos sin hojas, coloreando sus contornos en un fondo de tinte violáceo [...] (Trad. de Mersoye, 119).

Un atardecer en que la ventana estaba abierta y, sentada en el reborde, acababa de ver a Lestiboudois, el sacristán, recortando el boj, Emma oyó de repente sonar el Ángelus. [...] Por el enrejado del cenador y más allá, rodeándola, se veía el río en la pradera, donde dibujaba en la hierba sinuosidades inconcretas. El vaho de la noche pasaba entre los álamos sin hojas y difuminaba los perfiles en una tonalidad morada [...] (Trad. de Gallego, 137).

Una tarde en que la ventana estaba abierta y que, sentada junto a ella, Emma acababa de ver a Letisboudois, el sacristán, podando el boj, oyó de pronto el toque del ángelus. [...] Por los barrotes del cenador y más allá, todo alrededor, se veía el río en la pradera dibujando sobre la hierba sinuosidades vagabundas. El vaho del atardecer pasaba entre los álamos sin hojas, difuminando sus contornos con un tinte violeta [...] (Trad. de Armiño, 150).

Una noche en que la ventana estaba abierta, Emma, sentada en el alféizar, acababa de ver a Lestiboudois, el pertiguero, podando el boj, cuando, de repente, oyó sonar el ángelus. [...] A través del cercado vegetal del cenador y rodeándolos a cierta distancia, se divisaba el río en el prado, que dibujaba en la hierba erráticas sinuosidades. El vaho del atardecer se filtraba entre los chopos desnudos, difuminando sus perfiles con un tinte violeta [...] (Trad. de Albiñana, 148).

Las traducciones analizadas presentan las habituales diferencias en cuanto a opciones sintácticas o léxicas (sacristán/pertiguero; grafía de Angelus; álamos/chopos; violáceo/violeta/morado). Es de destacar la traducción de «soir» por «noche» por parte de Gallego y Albiñana, que parece incongruente con el momento de la acción: la caída de la tarde, cuando todavía hay visibilidad. Habría que señalar, igualmente, el error de Mersoye, que presenta a Lestiboudois «torneando un palo».

\section{Ejemplo 3 Madame Bovary, II, 7}

Léon se va a París a terminar sus estudios de Derecho y Emma, a fuerza de pensar en él, idealiza la relación que no llegaron a tener.

Léon réapparaissait plus grand, plus beau, plus suave, plus vague ; quoiqu'il fût séparé d’elle, il ne l'avait pas quittée, il était là, et les murailles de la maison semblaient garder son ombre. Elle ne pouvait détacher sa vue de ce tapis où il avait marché, de ces meubles vides où il s'était assis. La rivière coulait toujours, et poussait lentement ses petits flots le long de la berge glissante (Flaubert, 171).

Un Léon más alto, más guapo, más delicado, más impreciso, se le volvía a aparecer, y aun cuando se hubiera separado de ella, no la había abandonado, seguía allí, y las paredes de la casa parecían conservar su nombre. Emma no podía apartar sus ojos de aquella alfombra que él había pisado, de aquellos sillones vacíos en los que él se había sentado. El río seguía fluyendo y arrastraba lentamente sus leves ondas a lo largo de la ribera escurridiza (Trad. de Bravo, 201).

León reaparecía más grande, más hermoso, más dulce, más difuso. Aunque alejado de ella, no la había abandonado, estaba allí. Las paredes de la casa parecían conservar su sombra. No podía ella desviar su vista de la alfombra que él 
había pisado, de las sillas donde se sentó. El río corría siempre y empujaba con lentitud sus pequeñas ondas a lo largo del ribazo resbaladizo (Trad. de Mersoye, 131).

Volvía a ver a Léon más alto, más guapo, más dulce, más inconcreto; aunque estuvieran separados, no la había dejado, estaba allí y en las paredes de la casa parecía conservarse su sombra. Emma no podía apartar los ojos de esa alfombra que él había pisado, de esos muebles vacíos donde él se había sentado. El río seguía fluyendo e impulsaba despacio las olas menudas a lo largo de la orilla resbaladiza (Trad. de Gallego, 151).

Léon se le volvía a aparecer más alto, más guapo, más dulce, más impreciso; aunque estuviera separado de ella, no la había dejado, estaba allí, y las paredes de la casa parecían conservar su sombra. No podía apartar su vista de aquella alfombra que él había pisado, de aquellos muebles vacíos donde se había sentado. El río seguía fluyendo e impulsaba lentamente sus leves olas a lo largo de la resbaladiza ribera (Trad. de Armiño, 164).

Léon se le aparecía más alto, más guapo, más delicado, más etéreo; aunque no se hallara ya con ella, no la había abandonado, estaba allí, y las paredes de la casa parecían conservar su sombra. Emma no podía despegar la mirada de aquella alfombra por la que él había caminado, de aquellas sillas vacías donde se había sentado. El río seguía fluyendo, arrastrando lentamente sus pequeñas olas a lo largo de la margen resbaladiza (Trad. de Albiñana, 165).

En la traducción de Mersoye se aprecian calcos léxicos (grand/grande) y sintácticos (toujours), así como omisiones (vides). El resto, con las variaciones propias del estilo de cada traductor, se ajusta a los parámetros de una traducción de calidad. Sorprende, sin embargo, la traducción de «ombre» por «nombre» en la versión de Bravo.

\section{Ejemplo 4 Madame Bovary, III, 7}

Incapaz de abonar los ocho mil francos que debe, Emma se enfrenta al embargo judicial. Desesperada, se refugia en casa de la nodriza en espera de la ayuda de Léon.

Elle se souvenait... Un jour, avec Léon... Oh ! comme c’était loin... Le soleil brillait sur la rivière et les clématites embaumaient... Alors, emportée dans ses souvenirs comme dans un torrent qui bouillonne, elle arriva bientôt à se rappeler la journée de la veille (Flaubert, 396).

Se acordaba... de un día, con Léon... ¡Dios mío, qué lejos estaba todo aquello!... El sol brillaba sobre el río y las clemátides embalsamaban el aire con su aroma... Y así, arrastrada por sus recuerdos como por un impetuoso torrente, no tardó en venirle a la conciencia lo ocurrido durante la jornada de la víspera (Trad. de Bravo, 401).

Se acordaba de que un día con León... ¡Oh, qué lejano estaba aquello!... El sol brillaba por el río y las clemátides tormentosas y trepadoras embalsamaban el ambiente... Arrastrada por sus recuerdos, como un torrente ensordecedor, llegó a reconstruir la jornada de la víspera (Trad. de Mersoye, 302).

Recordaba... Un día, con Léon... ¡Ay, qué día tan lejano! El sol brillaba en el río y las clemátides olían bien. Entonces la arrastraron los recuerdos, como en el hervor de un torrente, y no tardó en acordarse del día anterior (Trad. de Gallego 351).

Recordaba... Un día, con Léon... ¡Ay!, qué lejos todo aquello... El sol brillaba sobre el río y las clemátides despedían su olor... Entonces, arrastrada por sus recuerdos como por un torrente hirviente, no tardó en acordarse de la jornada de la víspera (Trad. de Armiño, 362).

Recordaba un día, con Léon... ¡Ah, cuán lejos quedaba aquello!... Brillaba el sol sobre el río y las clemátides embalsamaban el aire... Al final, arrastrada por sus recuerdos como por los borbotones de un torrente, alcanzó a recordar la víspera (Trad. de Albiñana, 398).

Todas las traducciones reproducen el original, con los matices de estilo propios de cada traductor. Llama la atención, sin embargo, la adición de los adjetivos «tormentosas y trepadoras» no presentes en el original, en la traducción de Mersoye. 


\section{Calidad de las traducciones}

Para evaluar la calidad de las traducciones, nos hemos servido del baremo propuesto por Íñiguez Rodríguez (2015) adaptándolo al caso analizado y señalando los errores antes comentados. Hemos anotado en la columna de cada traductor el tipo de error detectado en los fragmentos analizados, así como su frecuencia.

Tabla 1. Número de errores de comprensión y expresión identificados

\begin{tabular}{|c|c|c|c|c|c|}
\hline $\begin{array}{l}\text { Tipo de } \\
\text { error }\end{array}$ & Bravo & Mersoye & Gallego & Armiño & Albiñana \\
\hline Adición & & 1 & & & \\
\hline \multicolumn{6}{|l|}{ Ambigüedad } \\
\hline \multicolumn{6}{|l|}{ Cultura } \\
\hline Omisión & & 2 & & & \\
\hline \multicolumn{6}{|l|}{ Registro } \\
\hline $\begin{array}{c}\text { Transmisión } \\
\text { de significado }\end{array}$ & 1 & 1 & 1 & & 1 \\
\hline \multicolumn{6}{|l|}{ Gramática } \\
\hline \multicolumn{6}{|l|}{ Léxico } \\
\hline Puntuación & & & 1 & & \\
\hline \multicolumn{6}{|l|}{ Ortografía } \\
\hline $\begin{array}{l}\text { Orden de las } \\
\text { palabras }\end{array}$ & & & & & \\
\hline
\end{tabular}

Algunas de las categorías (cultura, gramática...) han quedado vacías, debido sobre todo a lo reducido de la muestra analizada. Consideramos que para extraer datos más fidedignos, sería necesario realizar un estudio basado en fragmentos más amplios. Aun así, creemos que este análisis puede proporcionar algunas pistas sobre la calidad de las traducciones analizadas.

Los errores que se han identificado con mayor frecuencia fueron los de comprensión (7 errores), mientras que solo hemos detectado un error de expresión, en concreto, de puntuación. La traducción que presenta más cantidad y variedad de errores es la de Mersoye. El resto se encuentra en una misma horquilla en lo que a calidad se refiere, a un nivel bastante similar.

\section{Conclusión}

Somos conscientes de que los resultados de la aplicación de este baremo pueden ser poco representativos para valorar la calidad de estas traducciones, al fundamentarse en el análisis de unos cuantos fragmentos. De igual modo, estamos convencidos de que ninguna traducción sale indemne cuando se le aplica un análisis de este tipo, centrado en el error. Además, como afirma Íñiguez Rodríguez (2015: 200), «hay que tener en mente que dado que la calidad es más un valor relativo que absoluto, no existe un método infalible para evaluarla, y siempre hay un margen que atribuir al evaluador». Con todo, esta pequeña muestra nos ha permitido confirmar la apreciación global que habíamos obtenido en la lectura de estas traducciones: las versiones de Bravo, Gallego, Armiño y Albiñana son productos de calidad que están a la altura de la talla literaria del original. La traducción de Mersoye, por el contrario, es un producto de poca calidad, más propio de momentos pretéritos de la traducción de este clásico que de los comienzos de siglo XXI.

Este análisis nos permite aventurar que, en el caso de Madame Bovary, las últimas versiones publicadas en la Península no han supuesto una mejora sustancial de la calidad con cada nueva retraducción, sino que en su conjunto se han 
mantenido en un nivel alto, en consonancia con el perfil de sus traductores, con la salvedad de la versión de Mersoye. Las razones de las constantes retraducciones de esta obra responden, más bien, a políticas del sector editorial, muy volcado en las colecciones de clásicos, con una estrategia basada en la presentación y promoción de las nuevas traducciones como novedades editoriales. Sellos pequeños y medianos han apostado por sus propias colecciones, rentables por no tener que abonar derechos de autor y por la ausencia de riesgo literario. Esto ha redundado en un esfuerzo traductor sostenido en torno a esta obra, que no se puede justificar en la mejora de la calidad de las traducciones.

\section{Referencias bibliográficas}

Bravo Castillo, Juan (1995). «Madame Bovary et ses versions à l'espagnol» en Lafarga, Francisco; Ribas, Albert y Tricás, Mercedes (eds.). La traducción. Metodología, Historia, Literatura. Ámbito hispanofrancés. Barcelona: P.P.U. 398-399.

Bravo Castillo, Juan (2009). «Flaubert, Gustave» en Lafarga, Francisco y Pegenaute, Luis (coord.). Diccionario histórico de la traducción en España. Madrid: Gredos. 393-395.

BuEno García, Antonio (1995). «La última Madame Bovary. Un nuevo empeño de desagravio», en Hieronymus Compluntensis. El mundo de la traducción 1. <http://cvc.cervantes.es/lengua/hieronymus/pdf/01/01_141.pdf> [Consulta: 01.12.15].

FLAUBERT, Gustave (1972). Madame Bovary. Paris: Gallimard.

Flaubert, Gustave (1993). Madame Bovary (trad. de Bravo Castillo, Juan). Madrid: Espasa Calpe.

Flaubert, Gustave (2010). Madame Bovary (trad. de Mersoye, Marie). Barcelona: Plutón.

FLAUBERT, Gustave (2012). La señora Bovary (trad. de Gallego Urrutia, María Teresa). Barcelona: Alba Editorial.

Flaubert, Gustave (2013). Madame Bovary (trad. de Armiño, Mauro). Madrid: Siruela.

FLAUBERT, Gustave (2014). Madame Bovary (trad. de Albiñana Serain, Javier). Barcelona: Vicens Vives.

Flaubert, Gustave (2014). Madame Bovary (trad. de Fondebrider, Jorge). Buenos Aires: Eterna Cadencia.

Flaubert, Gustave (2015). Madame Bovary (trad. de Nogueras, Pablo R.). Madrid: Mestas.

FONDEBRIDER, Jorge (2014). «Las versiones de Madame Bovary» en Flaubert, Gustave. Madame Bovary. Buenos Aires: Eterna Cadencia. 491-501.

Gine JANER, Marta (2011). «Les traductions de Flaubert en Espagne : esquisse d'un tableau» en Flaubert, $\mathrm{n}^{\circ}$ 6. <http://flaubert.revues.org/1654> [Consulta: 10 de marzo de 2016].

HARDT, Manfred (2014). «Les images de Flaubert» (4 ${ }^{\mathrm{e}}$ partie de Das Bild in der Dichtung, 1966. Traduction française et présentation par Philippe Dufour et Nathalie Petibon) en Flaubert $\mathrm{n}^{\circ}$ 11. <http://flaubert.revues.org/2297> [Consulta: 16 de marzo de 2016].

HERNÁNDEZ GueRrero, María José (en prensa). «Traducción y estrategia editorial: las últimas versiones españolas y argentinas de Madame Bovary» en Zaro Vera, Juan Jesús y Salvador Peña (eds.). De Homero a Pavese: Hacia un canon iberoamericano de clásicos universales.

ÍÑIgUEZ RodRÍGUEZ, Enrique (2015). «Un modelo de evaluación de la calidad para la traducción de poesía: Cavafis en español» en Sendebar, $n^{\circ}$ 26. 195-212.

PyM, Anthony (1998). Methods in Translation History. Manchester: St. Jerome.

Venuti, Lawrence (2004). «Retranslations. The Creation of Value» en Faull, Katherine M. (ed.). Translation and Culture. Lewisburg: Bucknell University Press. 25-38.

ZARO VerA, Juan Jesús (2007). «En torno al concepto de retraducción» en Zaro Vera, Juan Jesús y Ruiz Noguera, Francisco (eds.). Retraducir: una nueva mirada. La retraducción de textos literarios y audiovisuales. Málaga: Miguel Gómez Ed. 21-34. 